\title{
PERCEPÇÃO DE AUXILIARES E TÉCNICOS DE ENFERMAGEM SOBRE A LIDERANÇA ORGANIZACIONAL DE ENFERMEIROS DE UM HOSPITAL DO INTERIOR DO PARANÁ
}

\author{
PERCEPTION OF NURSING ASSISTANTS AND TECHNICIANS ABOUT \\ ORGANIZATIONAL LEADERSHIP OF NURSES IN A HOSPITAL IN THE \\ INTERIOR OF PARANA
}

\author{
Francine Giselle Keiko Yotoko Ferreira ${ }^{1}$ \\ Claudia Regina Magnabosco-Martins ${ }^{2}$
}

Envio: 15 set. 2011.

Aceitação: 15 mar. 2012.

\begin{abstract}
RESUMO
Esta pesquisa objetivou analisar como os técnicos e auxiliares de enfermagem percebem a liderança dos enfermeiros em um hospital. Os dados foram coletados por meio de questionário, respondidos por 50 profissionais. A interpretação dos dados seguiu as premissas da análise estatística descritiva simples e revela que a liderança dos chefes tem sido exercida de maneira positiva e funcional, favorecendo a execução do trabalho com satisfação e qualidade. Entretanto, necessita de um olhar diferenciado e de melhorias em alguns aspectos como organização e planejamento, maior quantidade de reuniões e treinamentos, bem como mais atenção no gerenciamento de conflitos. Tais aspectos são considerados importantes para a liderança e vêm sendo pouco utilizados e/ou desenvolvidos no local estudado.
\end{abstract}

Palavras-chave: Equipe de enfermagem. Liderança organizacional. Ambiente hospitalar.

\begin{abstract}
This study aimed to analyze how the Technical and Nursing Assistants perceive the leadership of nurses in a hospital. The data were collected through a questionnaire answered by 50 professionals. The data interpretation followed the assumptions of statistical analysis and show that the leadership of nursing managers has been exercised in a positive and functional way, favoring the execution of the job with satisfaction and quality. Nonetheless, it was identified the need for a new perspective view of the nursing assistants activities in some aspects such as organization and planning, more meetings and training, and more attention to conflict management. These aspects are considered important for leadership and have been underused and / or not fully developed in the studied area.
\end{abstract}

Keywords: Nursing team. Organizational leadership. Hospital environment.

Assistente social, especialista em gestão estratégica de pessoas (Unicentro). <fgkyotoko@yahoo.com.br>

2 Doutoranda em saúde coletiva (Unifesp), docente do curso de psicologia (Unicentro).<claudiamagnabosco@hotmail.com> 
O presente artigo trata da liderança no ambiente hospitalar, mais especificamente de como os técnicos e auxiliares de enfermagem avaliam a liderança exercida pelos enfermeiros. A ideia de investigar essa realidade ocorreu pela vinculação de trabalho da primeira autora na instituição que é campo da pesquisa e pela compreensão de que a equipe de enfermagem tem papel central nos hospitais, tanto por se tratar de um grande número de profissionais quanto pela relevância de suas funções nos serviços ali efetuados. É necessário entender como se dá a liderança nesse contexto, aspecto essencial para o desenvolvimento do trabalho, pois influencia diretamente na otimização da ação dos trabalhadores, dos materiais e equipamentos utilizados e, consequentemente, da qualidade na prestação dos serviços.

Atuando no contexto hospitalar, percebe-se o quanto é necessário desenvolver a habilidade de liderança para os enfermeiros, pois a complexidade desse tipo de organização vem exigindo essa prática. Preparados para atividades assistenciais de cuidado com o paciente, esses profissionais se deparam com um universo de funções administrativas que envolvem o gerenciamento de setor e de escalas de trabalho; o cumprimento de normas gerais e específicas, prazos e relatórios; reuniões com a equipe; manejo dos processos de comunicação e dos relacionamentos que se dão no trabalho; situações que envolvem conhecimentos e habilidades que vão além de sua formação específica e invadem o universo da prática da liderança, para a qual nem sempre há formação ou capacitação.

\section{O trabalho no contexto hospitalar}

Vivemos em uma sociedade marcada por intensas e rápidas mudanças que se processam especialmente no mundo do trabalho, com repercussões no dia a dia das pessoas (CUNHA; NETO, 2006), provocando transformações nos paradigmas e aumentando a intensidade da exigência no trabalho das pessoas e organizações, surgindo então uma "nova sintaxe à qual o desempenho e as pessoas são obrigadas a se adaptar" (ZANELLI; BORGES-ANDRADE; BASTOS, 2004, p. 15). A introdução de inovações tecnológicas e organizacionais são algumas das marcas das mudanças processadas, bem como o frequente debate quanto aos conceitos de globalização, competência, conhecimento, competitividade e liderança, por exemplo.

Compreender a liderança da equipe de enfermagem no ambiente hospitalar demanda conhecer melhor o contexto organizacional em que se encontra. De acordo com a Organização Mundial de Saúde (OMS), o hospital é

[...] parte integrante de uma organização médica e social cuja missão consiste em proporcionar à população uma assistência médico-sanitária completa, tanto curativa como preventiva, e cujos serviços externos irradiam até o âmbito familiar; o hospital é também um centro de formação de pessoal da saúde e de investigação biológica e psicossocial. (OMS, 2008).

Para Kurcgant (2005), as organizações de saúde têm como missão prevenir e curar doenças e reabilitar os indivíduos. Elas possuem espaço essencial na sociedade e se organizam de diversas formas, com diferentes entidades mantenedoras. A característica principal é trabalhar com o elemento humano e, nesse sentido, o paciente/cliente, a família do paciente/cliente e os profissionais que com eles trabalham constituem tanto a matéria-prima essencial como também, a mais importante ferramenta de trabalho a ser desenvolvida nas organizações de saúde.

Segundo Feuerwerker e Cecílio (2007), o contexto hospitalar apresenta-se como algo bastante complexo, envolvendo diversas especificidades, pois se trata de uma organização que ocupa lugar crítico na prestação de serviços de saúde, lugar de construção de identidades profissionais, com grande reconhecimento social, pois estão em debate a produção de cuidados, a busca da qualidade, a integralidade e a eficiência.

Conforme observaram Pinho, Abrahão e Ferreira (2003), Neumann (2007) e Feuerwerker e Cecílio (2007), o contexto hospitalar reúne peculiaridades no mundo do trabalho em que os profissionais estão direta ou indiretamente ligados à assistência aos pacientes. O cuidado por eles recebido é produto de um grande número de pequenos cuidados parciais de diferentes profissionais, que vão se complementando para compor o cuidado em saúde, constituído por uma complexa trama de atos e procedimentos.

A divisão de trabalho dentro do contexto hospitalar é extremamente precisa, necessitando de uma articulação eficiente e rápida dos profissionais para 
garantir a qualidade dos serviços prestados. Outras características muito próprias dele são as atividades ininterruptas (o trabalho é desenvolvido 24 horas) diariamente e em feriados e domingos; a concentração do maior contingente de atividades no período da manhã, pois geralmente nesse horário os médicos passam visita, prescrevem a medicação para o dia todo (necessitando que a enfermagem busque-as na farmácia), solicitam exames (fazendo com que a enfermagem leve os pacientes para realizá-los, ou acione os responsáveis para realizarem) e se efetuam os banhos dos pacientes. Há uma predominância de trabalhadores do sexo feminino, principalmente na enfermagem, explicado por Neumann (2007) pelo arquétipo em várias culturas atribuído às mulheres, relacionado à assistência e a higienização dos doentes como se fossem extensões dos trabalhos familiar e doméstico.

Tendo em vista a complexidade do trabalho desenvolvido nos hospitais, Pinho, Abrahão e Ferreira (2003) salientam fatores que intensificam a carga de trabalho de enfermagem como a grande variedade de procedimentos realizados, o constante aumento do conhecimento teórico e prático exigido, a dificuldade no fluxo de informações, o ritmo de trabalho, o ambiente físico, o estresse, o contato com o doente e as vivências de dor e morte. Nesse sentido, os serviços de saúde, em especial os hospitais, têm procurado incorporar rapidamente as novas tendências em ferramentas gerenciais tais como o balanced score-card; a gestão do conhecimento, da informação e das competências; a liderança coach; as unidades de negócios, modificando o panorama de sua administração, anteriormente relegada a modelos muitas vezes empíricos e pouco profissionalizados.

Assumindo esse discurso de necessidade desse contexto de mudanças, as empresas passam a exigir cada vez mais dos trabalhadores, pois entendem necessitar de pessoas que possam responder com rapidez a elas. Dessa forma, adaptar-se a novas situações, ser flexível, ter capacidade de relacionamentos, assumir desafios, entre outros, parecem requisitos imprescindíveis aos líderes neste novo milênio. Aos enfermeiros de um hospital é exigido este preparo para o momento atual, principalmente aqueles que coordenam as equipes de enfermagem, pois vários aspectos são importantes para um bom gerenciamento da enfermagem, dentre eles a liderança, que tem sido entendida como "necessária em todas as atividades e em todos os tipos de organização humana". (CHIAVENATO, 1994, p. 146).

Segundo Strapasson e Medeiros (2009), ao se pensar a temática liderança ao longo da história se pode classificá-la e agrupa-la em categorias: as características do líder com qualidades natas até os anos 1940; a perspectiva do estilo comportamental até os anos 1960; a abordagem contingencial ou situacional até início dos anos 1980. As ideias da gestão pelo simbólico, envolvendo a liderança carismática, a visionária e por fim a transformacional aparecem nos anos 1990, sendo a última percebida como uma teoria recente e relevante, pois os líderes que nela se baseiam conseguiriam promover a autoeficácia da equipe, valorizando a criatividade e a inovação, estimulando para a mudança. No cotidiano, observa-se que as teorias citadas têm sido utilizadas de modo concomitante até os dias atuais.

Bergamini (1994) relata que dois elementos parecem comuns a todas as definições de liderança: em primeiro lugar, elas conservam o denominador comum de que a liderança esteja ligada a um fenômeno grupal, isto é, envolva duas ou mais pessoas; e em segundo lugar, fica evidente que se trata de um processo de influência exercida de maneira intencional por parte do líder sobre seus seguidores.

Para o enfermeiro no contexto hospitalar, a habilidade de liderar se torna uma tarefa bastante complexa, em função da exigência de melhores resultados, da inovação e dos crescimentos constantes, sendo uma ferramenta entendida como imprescindível nesse peculiar processo de trabalho.

Para Gelbke e colaboradores (2009), liderar a equipe de enfermagem significa saber conduzir, organizando o trabalho da equipe, visando a um atendimento eficiente, pois o líder é o ponto de apoio para a equipe, quer na educação ou na coordenação do serviço, estimulando a equipe para desenvolver plenamente seu potencial, o que interferirá diretamente na qualidade da assistência. A liderança envolve compromisso, responsabilidade, empatia, habilidade para tomada de decisões, comunicação e gerenciamento de maneira efetiva e eficaz (PERES; CIAMPONE, 2006).

Em seu cotidiano, a prática do enfermeiro permeia quatro atividades essenciais: o cuidado, a gerência, a educação e a pesquisa - ou seja, aos 
enfermeiros cabem, entre outras tarefas diretamente relacionadas com sua atuação junto ao cliente, a liderança da equipe de enfermagem e o gerenciamento dos recursos físicos, materiais, humanos, financeiros, políticos e de informação para a prestação da assistência de enfermagem. $\mathrm{O}$ item pesquisa é mais presente em serviços de saúde de excelência, referências teórico-metodológicas e organizacionais no atendimento sanitário, algo menos corriqueiro na grande maioria dos serviços do país, realidade semelhante a do hospital em que a presente investigação ocorreu.

Em seus estudos, Kurcgant (2005), Peres e Ciampone (2006) e Backes e colaboradores (2008) relatam que no processo de trabalho gerencial os objetivos do enfermeiro são a organização do trabatho e das pessoas que com ele atuam na equipe de enfermagem e, para tanto, o enfermeiro utiliza um conjunto de instrumentos técnicos próprios da gerência, como o planejamento, o dimensionamento de pessoal de enfermagem, o recrutamento e a seleção de pessoal, a educação continuada e/ou permanente, a supervisão, a avaliação de desempenho e outros. Alguns conhecimentos que subsidiam o desenvolvimento da liderança são o planejamento, as estratégias gerenciais, a estrutura organizacional, a gerência de pessoas, o processo decisório, a administração do tempo, o gerenciamento de conflito, a negociação, o poder e a comunicação.

As pesquisas e autores citados demonstram que a liderança se torna uma tarefa bastante complexa, que os líderes vêm sendo cobrados por desempenhos que frutifiquem em melhores resultados, inovação e crescimentos constantes, sendo uma ferramenta importante para se pensar o processo de trabalho dos enfermeiros. A partir das reflexões, buscou-se compreender como os técnicos e auxiliares de enfermagem avaliam a liderança do enfermeiro no hospital investigado.

\section{Metodologia da pesquisa}

A pesquisa foi desenvolvida em um hospital filantrópico, considerado de média complexidade e referência para a região Centro-sul do Paraná, possuindo 145 leitos divididos em unidade de terapia intensiva neonatal, unidade de terapia intensiva adulto, clínica cirúrgica, clínica médica, alojamento conjunto (maternidade), psiquiatria e pediatria. Os atendimentos se dão $85 \%$ pelo Sistema Único de Saúde (SUS) e o restante entre particulares e convênios.
Em seu quadro, o hospital possui 240 funcionários, divididos em administrativos, enfermagem, limpeza e higienização, copa e cozinha e equipe multiprofissional (nutricionista, psicóloga, assistente social, terapeuta ocupacional, fisioterapeuta, fonoaudióloga e farmacêutica). O corpo de médicos é terceirizado, formado por aproximadamente 45 profissionais em diversas especialidades, como anestesiologia, cardiologia, clínica médica, cirurgia geral, urologia, psiquiatria, pediatria, neonatologia, intensivista, dermatologia, oftalmologia, radiologia, otorrinolaringologia, nefrologia, ortopedia e traumatologia, gastroenterologia, ginecologia e obstetrícia. A maior parte do quadro de funcionários é da enfermagem, que compreende auxiliares (13,75\%), técnicos de enfermagem $(36,25 \%)$ e enfermeiros $(6,25 \%)$, somando $56,25 \%$ do quadro de funcionários, o que está de acordo com Antunes e Costa, para que "os profissionais de enfermagem compreendem em torno de $60 \%$ do quadro de pessoal das instituições de saúde" (ANTUNES; COSTA, 2003, p. 833).

A equipe de Enfermagem é a maior força de trabalho do hospital, sendo composta de enfermeiros, que são os profissionais com formação superior; os técnicos de enfermagem, que possuem formação técnica pós-ensino médio; e os auxiliares de enfermagem, que fazem um curso específico ao concluírem o ensino fundamental, de acordo com o Conselho Federal de Enfermagem (COFEN, 1986), por meio dos artigos $6 .^{\circ}, 7 .^{\circ}, 8 .^{\circ}$ da Lei $7.498 / 1986$ que dispõe sobre a regulamentação do exercício da enfermagem e dá outras providências.

A investigação está baseada na pesquisa quantitativa, em que "os dados e as evidências podem ser quantificados, filtrados, organizados, mensurados e tabulados" (MARTINS; THEÓPHILO, 2007, p. 134-35), facilitando tanto a padronização quanto a reunião dos dados, compreendidos como expressão de uma qualidade que o número representa em relação a um fenômeno, situação, fato ou ação investigada. Para tanto, utilizou-se um questionário para a coleta de dados, contendo questões fechadas referentes aos dados sociodemográficos dos participantes e as atividades desenvolvidas pelos profissionais de enfermagem no contexto hospitalar no que tange a liderança dos processos de trabalho, comunicação e relacionamento das equipes que coordenam. No instrumento foi utilizada a denominação chefia em 
vez de líder com vistas à adequação à realidade do hospital. A cada questão, solicitava-se dos participantes uma única resposta escolhida em uma escala de Likert com uma variação gradual de cinco itens, como por exemplo "( ) sempre ( ) quase sempre ( ) às vezes ( ) raramente ( ) nunca".

O questionário foi apresentado e entregue aos auxiliares e técnicos de enfermagem de todos os setores do hospital no mês de julho de 2010. Dos 115 auxiliares e técnicos de enfermagem, apenas 70 foram abordados, pois havia 10 funcionários em férias, 4 em auxílio maternidade, 2 com atestado, 1 em auxílio-doença e 28 profissionais estavam de folga nos dias em que foram entregues os questionários. Dos 70 questionários entregues, apenas 50 foram devidamente preenchidos e devolvidos às pesquisadoras, $\mathrm{o}$ que representa $43,47 \%$ do total de técnicos e auxiliares de enfermagem da instituição. Posteriormente, os dados foram organizados em planilhas, realizando-se uma análise de frequência simples, e somados aos conhecimentos já dispostos na literatura eles possibilitaram a compreensão de como os respondentes avaliam a liderança dos enfermeiros no contexto hospitalar em que atuam.

Com o objetivo de conhecer mais sobre os funcionários, foi levantado o perfil sociodemográfico, exposto a seguir.
Como se pode visualizar na Tabela 1 , do total de 50 funcionários que responderam os questionários, $90 \%$ são técnicos de enfermagem, e a maioria é do sexo feminino (94\%), o que é uma característica comum na profissão. De modo geral, percebe-se que uma parte significativa dos funcionários trabalha na instituição há pelo menos 5 anos (37\%) e aproximadamente um terço está entre 6 a mais de 15 anos na instituição, com maiores chances de conhecer o seu funcionamento e suas chefias de maneira mais profunda que os mais novos. Em relação à idade, percebe-se que esses trabalhadores estão no auge do período produtivo no trabalho, entre 19 e 40 anos. Observa-se ainda que se trata de profissionais que em sua grande maioria possuem entre 2 e 15 anos de formação, o que remete à possibilidade de terem adquirido diferentes experiências, talvez no próprio local.

\section{Resultados e discussão}

O contato com os dados permitiu a construção de três eixos de análise: gestão das tarefas, gestão da comunicação e gestão dos relacionamentos, nos quais os resultados foram organizados em gráficos e tabelas e discutidos a partir da literatura da área.

Tabela 1 - Perfil sociodemográfico dos respondentes

\begin{tabular}{|c|c|c|c|c|c|c|c|c|}
\hline \multirow{2}{*}{ Idade } & \multicolumn{2}{|c|}{ Ocorrências } & \multirow{2}{*}{ Tempo de formação } & \multicolumn{2}{|c|}{ Ocorrências } & \multirow[t]{2}{*}{ Tempo no hospital } & \multicolumn{2}{|c|}{ Ocorrências } \\
\hline & Abs. & $\%$ & & Abs. & $\%$ & & Abs. & $\%$ \\
\hline 19 a 24 anos & 13 & 26 & Menos de 1 ano & 01 & 02 & Menos de 1 ano & 02 & 04 \\
\hline 25 a 29 anos & 07 & 14 & 2 a 3 anos & 18 & 36 & 2 a 3 anos & 03 & 27 \\
\hline 30 a 35 anos & 17 & 34 & 4 a 5 anos & 08 & 16 & 4 a 5 anos & 18 & 37 \\
\hline 36 a 41 anos & 06 & 12 & 6 a 10 anos & 13 & 26 & 6 a 10 anos & 08 & 16 \\
\hline 42 a 47 anos & 05 & 10 & 11 a 15 anos & 06 & 12 & 11 a 15 anos & 02 & 04 \\
\hline Mais de 48 anos & 02 & 04 & Mais de 15 anos & 04 & 08 & Mais de 15 anos & 06 & 12 \\
\hline
\end{tabular}

\begin{tabular}{c|c|c|c|c|c}
\hline Função & \multicolumn{2}{|c|}{ Sexo } & \multicolumn{2}{|c}{} \\
\hline $\begin{array}{c}\text { Auxiliar de } \\
\text { enfermagem }\end{array}$ & 05 & 10 & masculino & 03 & 06 \\
\hline $\begin{array}{c}\text { Técnico de } \\
\text { enfermagem }\end{array}$ & 45 & 90 & feminino & 47 & 94 \\
\hline
\end{tabular}

Fonte: Dados da pesquisa. 


\section{Gestão das Tarefas}

Neste eixo, foram dispostas as respostas às questões que dizem respeito à organização dos aspectos mais concretos e técnicos do trabalho dos enfermeiros no que tange à organização, planejamento e acompanhamento das tarefas, a distribuição de escalas, os treinamentos e as reuniões.

Quando questionados se a chefia de enfermagem organiza as atividades do turno de trabalho, mais da metade dos funcionários afirmou que as atividades são organizadas, o que não é visto da mesma forma para um terço deles, como se verifica no Gráfico 1. Em decorrência desses resultados, percebe-se a necessidade de as chefias se organizem com a finalidade de melhorar o andamento do trabalho. Uma estratégia seria a de reuniões mais frequentes, nas quais funcionários e chefias tivessem a possibilidade de discutir as atividades a serem desempenhadas, bem como a elaboração da escala mensal de atividades (predeterminada pela chefia) nos casos em que há rodízio de funções.

Gráfico 1 - Organização das atividades do turno de trabalho

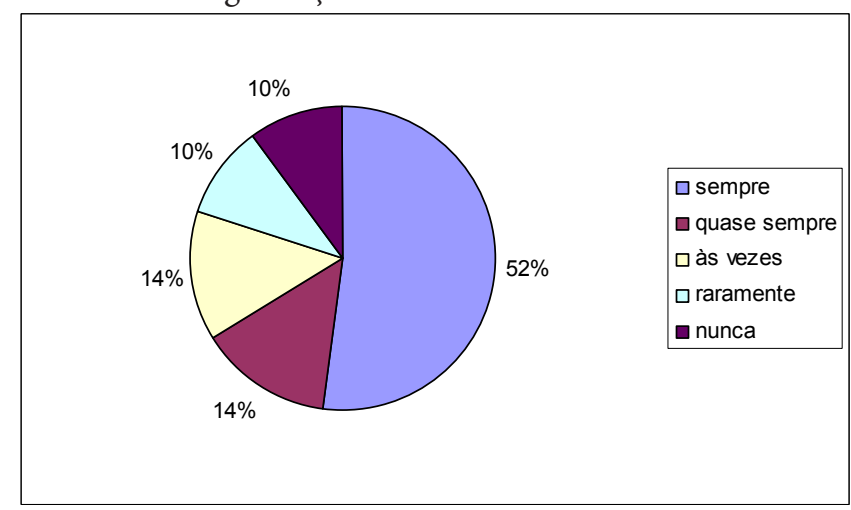

Fonte: Dados da pesquisa.

Massarollo (1994) relata que a elaboração de escalas diárias de atividades permite dividir as atividades de enfermagem de maneira equitativa entre os elementos da equipe, a fim de garantir que a assistência de enfermagem seja prestada evitando sobrecarga para alguns funcionários e ociosidade para outros. Assim, a organização das atividades do turno deve ser elaborada pelo enfermeiro responsável pelo plantão, discutindo com a equipe o rodízio nas diferentes atividades, considerando-se a clientela, as necessidades da unidade e a equipe de trabalho.
Segundo Kurcgant (2005), a atividade de organizar e planejar é uma tarefa que se torna imprescindível tendo em vista a complexidade de uma organização hospitalar, pois permite ampliar a análise de problemas e, consequentemente, tende a qualificar os processos decisórios.

Gráfico 2 - Realização do planejamento das tarefas

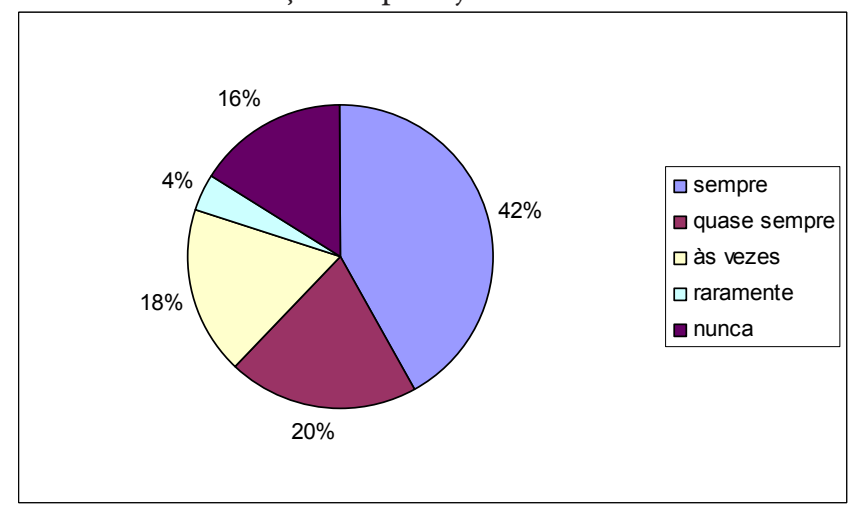

Fonte: Dados da pesquisa.

Para $62 \%$ dos funcionários, o planejamento das tarefas é realizado sempre ou quase sempre, mas ao se somarem as respostas "às vezes", "raramente" e "nunca", tem-se o valor de $38 \%$, número considerável de insatisfação nesse quesito. Esse dado mostra que existe a necessidade de planejar melhor as tarefas. Ciampone (1991) destaca que, em face de o ambiente hospitalar estar em constantes mudanças técnicas e sociais, o planejamento tem enorme importância, pois propicia meios de compreensão, antecipação, cooperação e exploração das mudanças. Assim, o planejamento propicia o suporte para a tomada de decisões e até mesmo a implementação de programas e propostas que se deseja viabilizar objetivando a construção de uma assistência de melhor qualidade, ao mesmo tempo em que permite traçar ações que ampliem a análise de problemas.

Ainda sob a óptica da gestão das tarefas, questionou-se sobre as escalas de trabalho. No gráfico 3, a maioria (74\%) dos profissionais relata se encontrar satisfeita com o sistema de trocas de escala, mas se poderia verificar a possibilidade de atender às necessidades dos $20 \%$ que a consideram ruim e péssima, permitindo-os se sentirem mais realizados no setor em que preferem trabalhar, e consequentemente seu rendimento poderá melhorar. 
Gráfico 3 - Sistema de trocas na escala

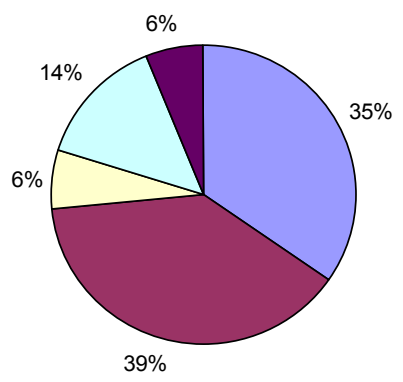

Fonte: Dados da pesquisa.

Questionou-se aos auxiliares e técnicos se deveria haver discussão sobre a troca de escala. Observa-se no Gráfico 4 que as pessoas querem assumir a responsabilidade na confecção das escalas e isso pode colaborar no processo de trabalho, já que os funcionários responderam que as chefias sempre ou quase sempre deveriam discutir a troca de escalas, somando-se $86 \%$.

Gráfico 4 - Discussão da troca de escala

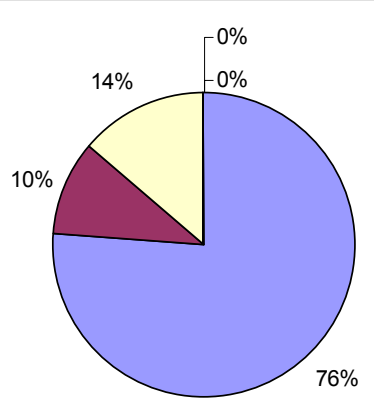

a nunca

Fonte: Dados da pesquisa.

Massarollo (1991) aborda a humanização ao se elaborar escala, com a distribuição dos elementos da equipe nos turnos de trabalho devendo ser planejada por todos os membros da equipe de enfermagem de modo a tentar atender às necessidades pessoais de cada um, da melhor forma possível. As exceções - fixar um elemento em um mesmo plantão por mais tempo que o previsto, conceder horários especiais etc. - deverão ser decididas e assumidas pela equipe. Essa autora sugere que os funcionários possam escolher os dias de folgas e quando ocorrerem várias solicitações para o mesmo dia, pode-se reunir os interessados a fim de se tentar um consenso.

Complementando isso, os técnicos e auxiliares ainda responderam que a troca de escalas deveria ser comunicada antecipadamente, seja com 30 dias, 15 dias ou 1 semana, sem que houvesse sequer uma resposta de que não se necessita criar estratégias de comunicação. Depreende-se assim que as pessoas querem ser informadas antecipadamente de mudanças em seu trabalho, justificando-as, podendo assim evitar conflitos e insatisfações, demonstrando respeito ao funcionário.

O acompanhamento do trabalho também faz parte do processo de gerenciamento de enfermagem. No Gráfico 5, apresenta-se como esse processo vem se desenvolvendo no quadro de enfermagem da instituição.

Gráfico 5 - Frequência do acompanhamento do trabalho

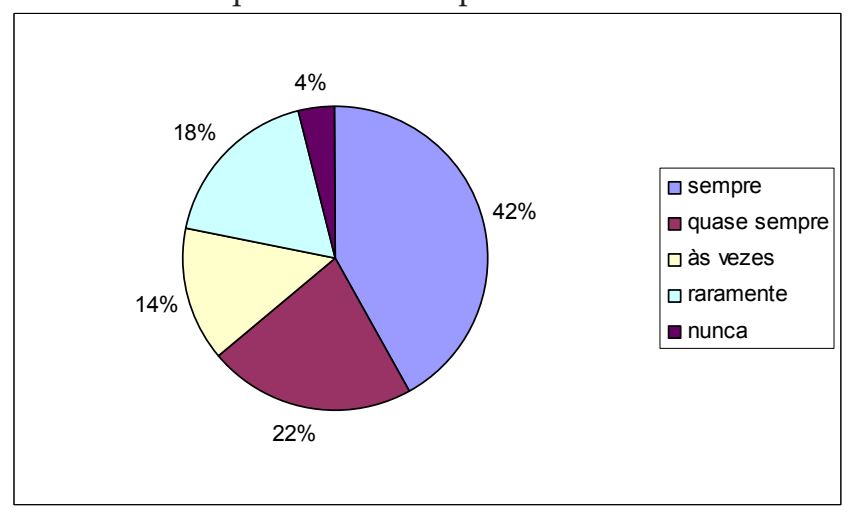

Fonte: Dados da pesquisa.

Note-se que $64 \%$ dos técnicos e auxiliares responderam que a chefia de enfermagem faz acompanhamento, mas aproximadamente um terço relata que ele é realizado somente às vezes, raramente ou nunca, sendo algo que talvez necessite de um olhar mais cuidadoso, tendo em vista a importância do acompanhamento do trabalho.

No Gráfico 6, percebe-se que $16 \%$ responderam que as chefias buscam promover treinamentos, porém a grande maioria (84\%) respondeu que isso ocorre somente às vezes, raramente ou nunca. Dessa forma, a prática de qualificação da equipe de enfermagem precisa de mais atenção e investimento dos líderes. 
Gráfico 6 - Promoção de treinamentos

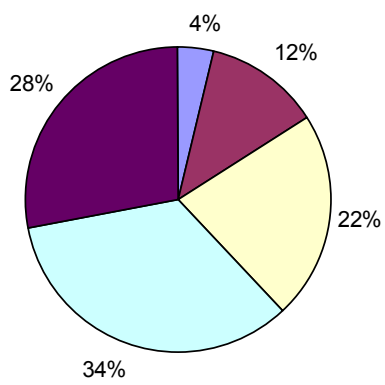

Outro fator que se torna importante no processo da gestão das tarefas do enfermeiro são as reuniões de equipe. No Gráfico 7, observamos que existe uma prevalência nas respostas "às vezes", "raramente" e "nunca", que quando somadas perfazem $66 \%$ das respostas, demonstrando que as reuniões não são uma prática comum dos enfermeiros enquanto líderes de equipes.

Abreu e colaboradores (2005) destacam que as reuniões de equipe são um instrumento importante para favorecer o crescimento profissional e pessoal dos membros e da própria equipe, sendo também forma de melhorar o desempenho para a prestação de assistência mais eficiente e eficaz. Para que isso ocorra, é fundamental as reuniões serem espaços de discussão, reflexão, troca de ideias e divulgação de conhecimento e não somente uma tentativa de resolver problemas emergenciais.

Gráfico 8 - Desenvolvimento das atividades do turno tico, capacitando o indivíduo para a realização eficiente de seu trabalho. Como já descrito, a realidade está em constante movimento e o trabalho em saúde passou e passa por inúmeras transformações que envolvem tecnologias de equipamento, medicamentos, procedimentos, atendimento clínico e relações de várias ordens e níveis de intensidade (CECÍLIO; MERHY, 2003), tornando cada vez mais complexo o processo de produção de cuidado. Tal processo passa pela capacitação dos profissionais, indicada por Ceccim (2005) para que aconteça em forma de educação permanente, envolvendo os líderes, que, em conjunto com os profissionais, podem encontrar formas de oferecer ao paciente melhor qualidade na assistência e ao mesmo tempo garantir condições de trabalho funcionais e agradáveis a todos.

Gráfico 7 - Realização de reuniões

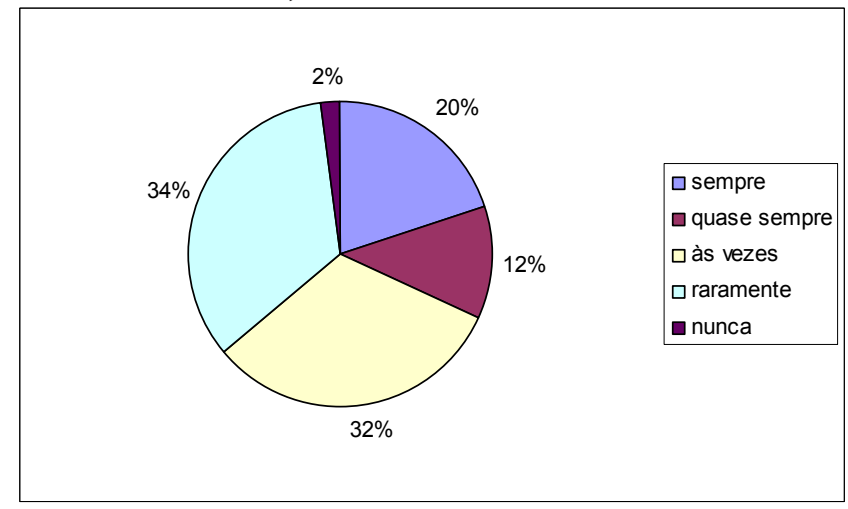

Fonte: Dados da pesquisa.

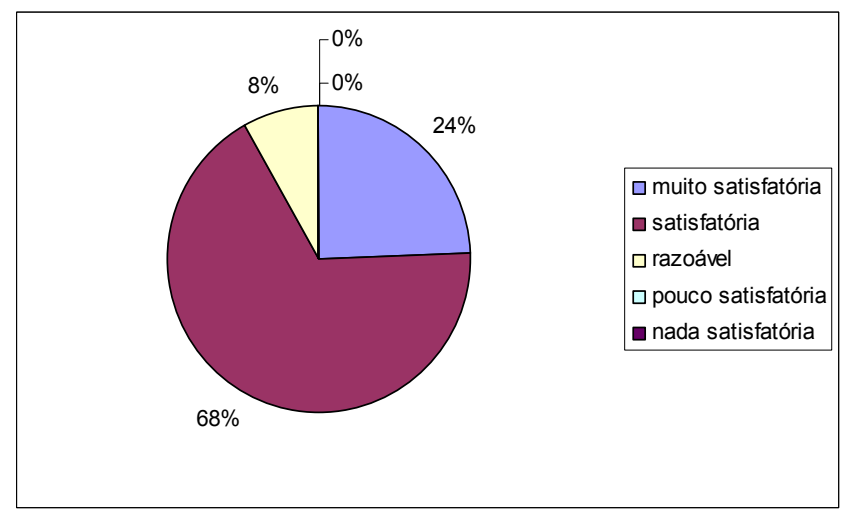

Fonte: Dados da pesquisa.

No Gráfico 8, pode-se perceber a predominância de respostas que demonstram que os técnicos e auxiliares de enfermagem desenvolvem satisfatoriamente o trabalho em seu turno (68\%), e apenas uma pequena parcela $(8 \%)$ respondeu que é razoável. Não se obtiveram as respostas "pouco satisfatória" ou "nada satisfatória". Embora, de forma geral, os números demonstrem um contentamento com o desenvolvimento do trabalho, pode haver um melhoramento no desenvolvimento das atividades do turno afinal, o número de "muito satisfatório" corresponde a $24 \%$. Esse melhoramento poderia ser concretizado com reuniões e treinamentos, permitindo ao funcionário trabalhar no setor com que mais se identifica, acompanhando o trabalho dos técnicos e auxiliares, bem como dando o retorno de como seu trabalho vem se desenvolvendo. 
Percepção de auxiliares e técnicos de enfermagem sobre a liderança organizacional de enfermeiros...

Tabela 2 - Informação e comunicação

\begin{tabular}{c|c|c|c|c|c|c|c|c|c|c}
\hline \multirow{2}{*}{ Questões } & \multicolumn{2}{|c|}{ Sempre } & \multicolumn{2}{c|}{$\begin{array}{c}\text { Quase } \\
\text { Sempre }\end{array}$} & \multicolumn{2}{c|}{ Às Vezes } & \multicolumn{2}{c|}{ Raramente } & \multicolumn{2}{c}{ Nunca } \\
\cline { 2 - 11 } & Abs. & $\%$ & Abs. & $\%$ & Abs. & $\%$ & Abs. & $\%$ & Abs. & $\%$ \\
\hline $\begin{array}{c}\text { Passa as informaçõesa todos da } \\
\text { mesma forma }\end{array}$ & 22 & 44 & 12 & 24 & 08 & 16 & 02 & 4 & 06 & 12 \\
\hline $\begin{array}{c}\text { Repassa a informação diretamente } \\
\text { a quem precisa }\end{array}$ & 24 & 48 & 08 & 16 & 12 & 24 & 02 & 4 & 04 & 8 \\
\hline $\begin{array}{c}\text { As informações repassadas } \\
\text { são de fácil entendimento }\end{array}$ & 30 & 60 & 09 & 18 & 05 & 10 & 06 & 12 & 00 & 0 \\
\hline $\begin{array}{c}\text { Ouve os questionamentos } \\
\text { e sugestões }\end{array}$ & 20 & 40 & 06 & 12 & 11 & 22 & 11 & 22 & 02 & 4 \\
\hline $\begin{array}{c}\text { Dá retorno de como seu trabalho } \\
\text { está sendo desenvolvido }\end{array}$ & 11 & 22 & 14 & 28 & 01 & 2 & 09 & 18 & 15 & 30 \\
\hline
\end{tabular}

Fonte: Dados da pesquisa

\section{Gestão da Comunicação}

A comunicação é fundamental para o processo de trabalho da enfermagem, pois é por meio dela que a equipe de enfermagem oferece e recebe informações para planejar, executar, avaliar e participar na assistência prestada ao paciente. A comunicação na área da saúde necessita ser homogênea, de modo que os profissionais transmitam sempre o mesmo significado, para evitar distorções das informações. $\mathrm{Na}$ Tabela 2 há elementos que demonstram como está a comunicação na equipe de enfermagem.

As informações necessárias ao trabalho são repassadas à maioria (68\%), e da mesma forma para todos, sendo que um número muito parecido de funcionários (cerca de 63\%) salientou que elas chegam a quem precisa. Porém, percebe-se que esse processo poderia melhorar, pois uma boa parcela de participantes $(32 \%)$ respondeu que às vezes, raramente e nunca as informações são repassadas a todos da mesma forma e $36 \%$ responderam que elas não chegam a quem deveria, necessitando de atenção, pois pode estar ocorrendo interferências no processo. Talvez analisar o fluxo da informação seja uma forma para se atingir todos que dela necessitam.

Em relação ao entendimento das informações, foram $78 \%$ os que responderam que a comunicação é sempre e quase sempre de fácil entendimento e $22 \%$ colocaram que às vezes e raramente entendem o que a chefia de enfermagem está repassando nas informações. Neste aspecto, a forma de repassar as informações necessita de melhorias, a fim de que todos possam entendê-las, tendo em vista a complexidade do trabalho exercido pelos técnicos e auxiliares de enfermagem.

Pinho, Abrahão e Ferreira (2003) relatam que a organização do trabalho hospitalar é marcada pelo ordenamento dos espaços físicos e pela estrutura rítmica da produção das atividades terapêuticas. Tal produção ocorre em meio a uma rede de relações sociais, nas quais as informações que asseguram a continuidade do cuidado ao paciente nas diferentes escalas de trabalho são comunicadas de forma verbal e/ou escrita, predominantemente pela transmissão de relatórios intra e interequipes (sobre o estado do paciente e a terapêutica manejada) e, de informativos sobre as rotinas administrativas. Essas informações são articuladas e geridas por estratégias diferenciadas, segundo a função do profissional, com vistas a um objetivo comum: o atendimento do paciente.

Mais da metade dos participantes (52\%) respondeu que sempre ou quase sempre as chefias ouvem questionamentos e sugestões, mas para $48 \%$ as chefias de enfermagem não o fazem, o que demonstra a necessidade de uma escuta qualificada, por meio da qual possam ocorrer melhorias no processo de trabalho e até mesmo para que os funcionários possam se sentir satisfeitos de que uma sugestão propiciou algo que trouxe melhorias.

Cerca de $50 \%$ dos funcionários disseram que somente às vezes, raramente e nunca é fornecido retorno de como o trabalho vem sendo desenvolvido. 
Isso corrobora Leite e Pereira (2005), ao relatarem que a avaliação de desempenho profissional individualizada e sistematizada não é uma prática comum nas organizações de saúde e nem na enfermagem. Mas fica evidente a necessidade de uma atenção especial ao retorno de como o profissional vem desenvolvendo/desempenhando suas atividades com o objetivo é aprimorar o desenvolvimento das pessoas, proporcionando crescimento profissional e pessoal e alcançando os objetivos organizacionais e principalmente a produção do cuidado.

Entende-se que esse processo deveria ser estabelecido em todas as organizações, o que não é uma tarefa fácil, pois muitas vezes se trata de avaliar aspectos subjetivos e, dessa maneira, é um desafio pensar instrumentos e estratégias de avaliação e consequentemente fornecer o retorno de como o profissional vem desenvolvendo seu trabalho ao longo de determinado período. Por exemplo, os gráfico 9 e 10 mostram como vem ocorrendo a comunicação na equipe de enfermagem e no turno de trabalho.

Gráfico 9 - Comunicação da equipe

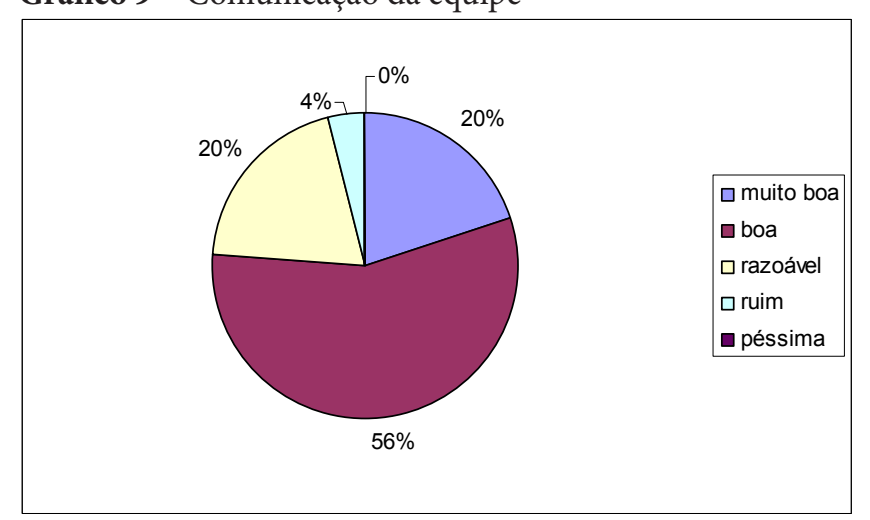

Fonte: Dados da pesquisa.

Verifica-se que para apenas $20 \%$ dos funcionários a comunicação na equipe de enfermagem é muito boa. Em contrapartida, no turno de trabalho esse número sobe para $42 \%$, como se pode verificar no Gráfico 10, demonstrando que a comunicação com as pessoas mais próximas é entendida como mais eficiente. Mas os números também indicam que a comunicação pode ser aprimorada, pois um grande número de funcionários respondeu que é boa e não muito boa.
Gráfico 10 - Comunicação no turno de trabalho

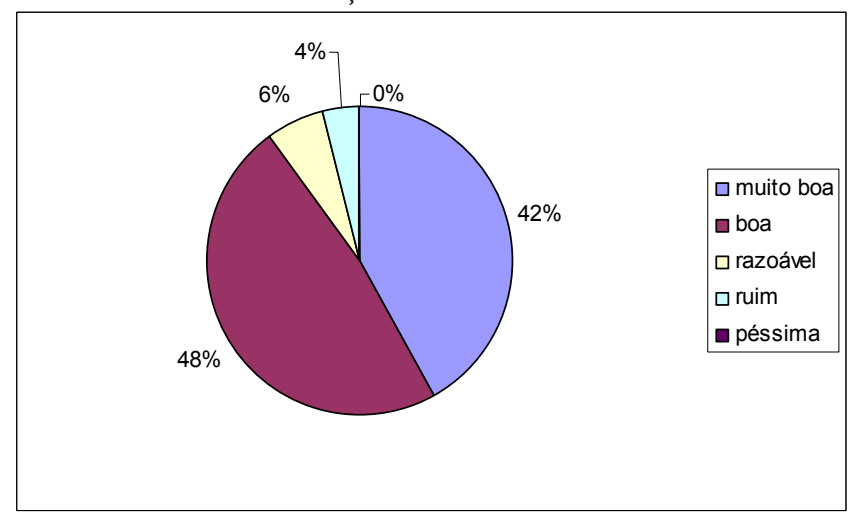

Fonte: Dados da pesquisa.

A comunicação pode ser um recurso para o sucesso na liderança organizacional, pois permite aos profissionais se relacionarem com o cliente, a instituição, a equipe médica e a enfermagem em busca da melhoria da qualidade da assistência prestada. Para Silva (2002), a comunicação efetiva é bidirecional, com interação, sendo necessário haver resposta e validação das mensagens ocorridas.

A tarefa do profissional de enfermagem ou da saúde é decodificar, decifrar e perceber o significado da mensagem da equipe com que trabalha. Assim, Galvão e colabordores (2000) descrevem que a comunicação é um meio para se aproximar das pessoas, compartilhar ideias e visões, aprimorar a compreensão sobre o trabalho de cada um, monitorar o desempenho e conhecer alternativas de futuro. É por meio da comunicação efetiva que o dirigente líder aprende a respeito dos subordinados e os informa sobre novas possibilidades, criando interdependências e fazendo se sentirem parte de uma equipe.

Dentro da organização hospitalar, comunicação efetiva é essencial porque dela decorrerá a continuidade do trabalho. Quando se trata de vida, é necessário que as informações repassadas sejam de fácil entendimento a quem delas necessita, e principalmente que sejam compreendidas, pois o contrário pode acarretar consequências irreversíveis à qualidade do atendimento. Nesse sentido, a gestão da comunicação constitui um elemento importante para o processo de trabalho da equipe de enfermagem, devendo ser foco de acompanhamento de seus líderes. 
Tabela 3 - Resolução de conflitos pela chefia de enfermagem

\begin{tabular}{c|c|c|c|c|c|c|c|c|c|c}
\hline \multirow{2}{*}{ Questões } & \multicolumn{2}{|c|}{ sempre } & \multicolumn{2}{c|}{$\begin{array}{c}\text { quase } \\
\text { sempre }\end{array}$} & \multicolumn{2}{c|}{ às vezes } & \multicolumn{2}{c|}{ raramente } & \multicolumn{2}{c}{ nunca } \\
\cline { 2 - 12 } & Abs. & $\%$ & Abs. & $\%$ & Abs. & $\%$ & Abs. & $\%$ & Abs. & $\%$ \\
\hline Resolve os conflitos no trabalho & 12 & 24 & 15 & 30 & 12 & 24 & 03 & 6 & 08 & 16 \\
\hline $\begin{array}{c}\text { Tem imparcialidade na forma de } \\
\text { resolução dos conflitos }\end{array}$ & 15 & 30 & 14 & 28 & 12 & 24 & 04 & 8 & 05 & 10 \\
\hline $\begin{array}{c}\text { Busca resolver conflitos entre } \\
\text { equipe e outros profissionais }\end{array}$ & 17 & 33 & 12 & 23 & 10 & 19 & 05 & 10 & 08 & 15 \\
\hline
\end{tabular}

Fonte: Dados da pesquisa.

\section{Gestão dos Relacionamentos}

A gestão dos relacionamentos é uma tarefa fundamental da liderança, uma vez que os conflitos fazem parte do contexto organizacional e da complexidade humana. No local de trabalho, são frequentes as situações conflituosas esperadas, uma vez que conflitos são prováveis em decorrência de confrontos de ideias, muitas vezes provocadas por desejos, interesses e necessidades diferentes.

$\mathrm{Na}$ Tabela 3, pode-se observar como, na percepção dos respondentes, as chefias de enfermagem lidam com a resolução de conflitos.

Quando da existência de conflitos no trabalho em geral, foram $54 \%$ os funcionários que responderam que sempre ou quase sempre são resolvidos com a atuação participante do líder, porém, para $46 \%$, às vezes, raramente ou nunca são resolvidos. Ao pensarem o conflito entre os técnicos e auxiliares de enfermagem e outros profissionais, os dados obtidos nas repostas foram bem parecidos, sendo que para $56 \%$ os conflitos são sempre ou quase sempre resolvidos e para $44 \%$, às vezes, raramente ou nunca. Portanto, a maioria dos participantes está satisfeita com a resolução de conflitos no hospital em que trabalha. Por outro lado, $46 \%$ e $44 \%$ demonstram a necessidade de criar estratégias para melhorar. Seria interessante que os líderes desenvolvessem capacidade perceptiva em relação a sua equipe, voltando sua atenção para os aspectos que possam influenciar o ambiente profissional e neles atuar. Sobre a imparcialidade na forma de resolução, foram $58 \%$ os funcionários que perceberam uma diferenciação na forma de resolução, havendo privilégios, e 44\% responderam que isso ocorre apenas às vezes, raramente ou nunca.

Não se pretendeu nesta pesquisa levantar as possíveis causas geradoras de conflito na equipe de enfermagem, mas Jericó e Peres (2008) afirmam ser falta de clareza na missão, visão e valores da instituição; depreciação do ambiente físico de trabalho; formas distintas de contratação; má organização no serviço de enfermagem; relacionamentos pessoais e grupais conflituosos; e ainda comunicação e liderança pouco desenvolvidas. Encontramos também relatos de falta de definição de papéis, invasão de espaços por outros profissionais, alta rotatividade, falta de pessoal, problemas externos ao trabalho, sentimentos de desvalorização, dificuldade com pacientes e familiares, falta de confiança e clima organizacional. Hipotetiza-se que aprimorar esses fatores pode melhorar a resolução dos conflitos no trabalho.

No Gráfico 11, é apresentado como os respondentes avaliam as formas de as chefias manejarem os conflitos.

Gráfico 11 - Formas de manejo dos conflitos

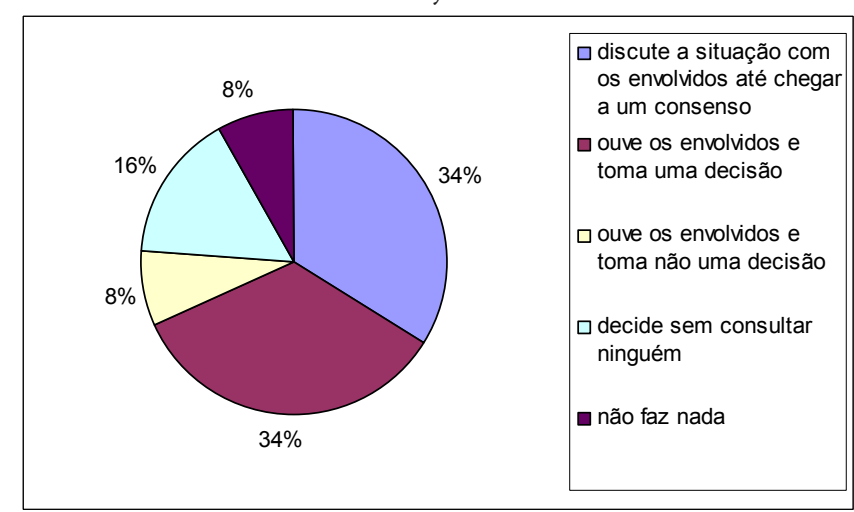

Fonte: Dados da pesquisa.

Percebe-se que para $68 \%$ dos funcionários existe escuta durante o conflito, sendo que para $8 \%$ o chefe até ouve a queixa, mas não toma nenhuma decisão e para $24 \%$ ele nem as ouve. Jericó e Peres 
(2005) apontam que os enfermeiros apresentam uma forma passiva na resolução dos conflitos, atitude que não vai ao encontro dos propósitos da gestão contemporânea em enfermagem, que sugere uma ação mais assertiva da equipe de enfermagem junto a outros profissionais. Os dados apresentados no Gráfico 11 demonstram necessidade de melhorias na forma de resolução dos conflitos na instituição investigada, principalmente na questão relacional, de atenção e escuta da chefia para com os funcionários ou promovendo o diálogo entre as partes conflitantes. Ciampone e Kurcgant (2005) sugerem que as diferentes leituras e interpretações da realidade, segundo os diferentes agentes, devem ser elementos considerados quando se busca o entendimento do conflito.

Essas duas autoras sugerem que os conflitos podem ser administrados por pelo menos quatro estratégias diferentes: acomodação, dominação, barganha/ compromisso e solução integrativa de problemas.

$\mathrm{Na}$ acomodação, busca-se uma harmonia por meio do encobrimento dos problemas, porém o conflito pode ressurgir, tornando mais difícil a sua compreensão.

$\mathrm{Na}$ dominação, o poder é levado ao extremo, quando a parte mais forte impõe a solução que prefere.

Já no estilo barganha/compromisso, cada parte cede um pouco, a fim de resolver o conflito.

Por fim, na solução integrativa de problemas, busca-se satisfazer as exigências das duas partes por meio de soluções alternativas, identificando as consequências para ambas as partes e escolhendo a alternativa mais favorável (CIAMPONE; KURCGANT, 2005).

Jericó e Peres (2005) relatam que as táticas para lidar com o conflito sugerem comunicação assertiva, negociação, acomodação, compromisso, competição e colaboração.

A forma mais comum de resolver um conflito é por meio da negociação. Habilidades de negociação bem-sucedidas resolvem conflitos e encorajam a colaboração, gerando um ambiente positivo de trabalho.

Em todo esse processo, o enfermeiro deve gerir os conflitos de modo a produzir bons resultados em vez de um ambiente de trabalho hostil e improdutivo. Existem meios e ferramentas para solucioná-los, propiciando situações de aprendizagem e transformando-os em instrumento de crescimento pessoal e profissional.
Ainda quanto à gestão dos relacionamentos, foi perguntado aos funcionários se a chefia de enfermagem facilita a participação no dia a dia de trabalho, conforme mostra o Gráfico 12. Percebe-se que $22 \%$ responderam que sempre o faz e $30 \%$, que raramente e nunca, demonstrando que esse quesito pode ser melhorado no hospital em estudo. Esse melhoramento poderia ser concretizado por meio de reuniões em que os funcionários tivessem oportunidade de expressar suas ideias, informações, críticas e avaliações até mesmo em relação à forma de atuação das chefias, a fim de proporcionar melhor aproveitamento do potencial das pessoas que fazem parte da equipe, favorecendo um trabalho integrado.

Gráfico 12 - Facilitação da participação da equipe

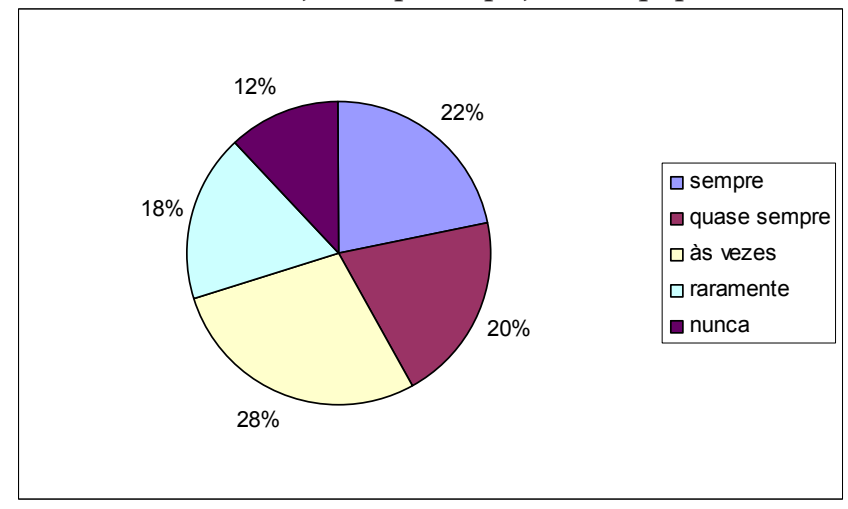

Fonte: Dados da pesquisa.

\section{A avaliação geral}

Ao final das perguntas mais específicas, os participantes tinham acesso a perguntas abertas e amplas, que remetiam a como avaliavam a si mesmos e o trabalho de sua equipe, e como viam o comprometimento e a competência de suas chefias. Com esses resultados, foi possível perceber o quanto os participantes se colocaram nas respostas que dirigiram para avaliar a liderança de seu chefe. Por unanimidade, os participantes responderam que são muito comprometidos (44\%) e comprometidos (56\%) com seu trabalho, enquanto seus chefes são muito comprometidos $(26 \%)$, comprometidos $(50 \%)$, razoavelmente comprometidos $(8 \%)$, pouco comprometidos (12\%) e descomprometidos (4\%). Tais números demonstram que, para esses técnicos, os chefes são menos comprometidos que eles mesmos, que por sua vez se apresentam como a parte da relação que não tem falhas, dado muito relevante ao se considerar 
todas as avaliações realizadas, de modo a colocar em dúvida o quanto eles se incluem no sucesso ou não da liderança organizacional.

Rodriguez, Trevizan e Shinyashiki (2008), em estudo realizado sobre o comprometimento organizacional e profissional no setor da saúde, revelam que o comprometimento é fundamental para o efetivo desempenho dos profissionais e para o cumprimento dos objetivos e metas organizacionais. Dizem ainda que cabe às organizações de saúde considerar a situação e os benefícios que podem ser gerados com o comprometimento do indivíduo.

Os dados relacionados ao comprometimento dos chefes se repetem de maneira aproximada à da percepção de sua competência, já que $20 \%$ dos entrevistados responderam que a chefia é muito competente e $56 \%$ que é competente, mas para $10 \%$ razoável, para $2 \%$, pouco competente e para $12 \%$, incompetente. Nesse sentido, em âmbito geral, a análise da competência geral dos chefes foi positiva, o que é essencial para a liderança, pois expressa a confiança dos liderados de que aquele que coordena o grupo tem condições para fazê-lo.

Medeiros e Silva (2007) relatam que nos últimos tempos se tem discutido sobre a importância do comprometimento dos indivíduos nas organizações por diversas razões, dentre as quais a produtividade e o nível de qualidade do trabalho e das atividades; a velocidade na internalização de novas tecnologias e novos conhecimentos; a otimização da capacidade; a criação de oportunidades para a aplicação das competências; a velocidade de respostas para o ambiente/ mercado.

A falta de comprometimento das pessoas com o grupo tende a gerar uma série de dificuldades, como pouco engajamento com as atividades, alta rotatividade, falta de empenho para resolver problemas porque os integrantes não se sentem parte do grupo, e não apresentam grandes inovações ou diferenças porque em parte não conseguem se envolver com o grupo e apresentar sugestões, ideias ou dedicação. Todas essas situações não são de origem apenas individual, mas se expressam em cada trabalhador, potencializando reclamações e desentendimentos, dificuldades no processo de trabalho e na consecução da produção, bem como no menor interesse no aperfeiçoamento ou desenvolvimento nas atividades em que atuam. No âmbito geral, pode ocorrer a falta de comprometimento de vários trabalhadores em conjunto, o que por sua vez pode se transformar em uma fuga da responsabilidade ao buscarem assumir o mínimo possível em situações de responsbilidade grupal (MOSCOVICI, 2001; RODRIGUEZ; TREVIZAN; SHINYASHIKI, 2008; MEDEIROS; SILVA, 2007). Assim, torna-se essencial que trabalhadores, líderes e gestores possam pensar e discutir o que representa essa falta de comprometimento em termos institucionais, sociais e culturais e, desse modo, possam coletivamente engendrar propostas para seu enfrentamento.

\section{Considerações finais}

Foi possível verificar neste estudo que a liderança de enfermagem no ambiente hospitalar estudado pode se expressar em diferentes aspectos: situações que envolvem tomada de decisão, resolução de conflitos, articulação de saberes e profissionais, comunicação, relações interpessoais, organização e planejamento dos processos de trabalho. Tornou-se visível que há a necessidade do exercício de habilidades essenciais, que por sua vez exigem um processo contínuo de desenvolvimento do líder.

Os resultados encontrados neste estudo demonstraram que alguns aspectos como organização e planejamento, reuniões, treinamentos e gerenciamento de conflitos necessitam um olhar diferenciado das chefias avaliadas, tendo em vista que tais aspectos são importantes para a liderança e vêm sendo pouco utilizados e/ou desenvolvidos no local estudado. Por outro lado, em linhas gerais, a avaliação é de que a liderança dos chefes tem sido exercida de maneira positiva e funcional, o que favorece a execução do trabalho com satisfação e qualidade, e ela pode melhorar para cerca de um terço dos funcionários. Para tanto, o comprometimento relatado pelos técnicos e auxiliares fornece indícios de que há envolvimento, que eles possuem vontade de fazer acontecer, e de que isso pode ser potencializado para melhorar o trabalho da equipe de enfermagem, superando as falhas que eles mesmos apontaram.

Salienta-se que uma limitação desta pesquisa é o fato de, para se garantir o sigilo dos dados dos respondentes, não haver identificação dos setores aos quais os técnicos e auxiliares pertencem, e portanto não houve a identificação das chefias avaliadas, impedindo a 
especificação dos dados, ocorrendo a generalização para todo o hospital. Esse pode ser foco de uma nova pesquisa.

A liderança é tida como uma das principais competências a ser desenvolvida pelos profissionais de enfermagem. Nesse sentido, as organizações precisam investir na formação de lideranças por meio da educação permanente, podendo ser um dos aspectos a se desenvolver também no ensino superior em enfermagem, ao se acrescentar aos currículos conteúdos e estratégias que viabilizem o aprendizado sobre liderança e o desenvolvimento de habilidades e competências para dela usufruir. Acredita-se que o investimento na formação de enfermeiros-líderes os preparará para serem agentes de transformação e inovações que objetivem e concretizem melhorias na organização, nas equipes de enfermagem e, principalmente, na assistência ao paciente, ou seja, nos diferentes pontos e níveis da produção do cuidado em saúde.

\section{Referências}

ABREU, L. O. et al. O trabalho de equipe em enfermagem: revisão sistemática da literatura. Revista Brasileira de Enfermagem, Brasília, v. 58, n. 2, mar.-abr., p. 203-07, 2005.

ANTUNES, A. V.; COSTA, M. N. Dimensionamento de pessoal de enfermagem em um hospital universitário. Revista Latino-americana de Enfermagem, Ribeirão Preto, v.11, n. 5, dez., p. 832-39, 2003.

BACKES, D. S. et al. O papel do enfermeiro no contexto hospitalar: a visão de profissionais de saúde. Ciência, Cuidado e Saúde, Florianópolis, v.7, n. 3, jul.-set., p. 319326, 2008.

BERGAMINI, C. W. Liderança: administração do sentido. São Paulo: Atlas, 1994.

CECCIN, R. B. Educação permanente em saúde: desafio ambicioso e necessário. Interface: comunicação, saúde e educação. Botucatu, v. 9, n. 16, p. 161-67, 2005.

CECILIO, L. C. O.; MERHY, E. E. O singular processo de coordenação dos hospitais. Saúde em Debate, Rio de Janeiro, v. 27, n. 64, p. 110-22, 2003.

CIAMPONE, M. H. T.; KURCGANT, P. Gerenciamento de conflitos e negociação. In: KURCGANT, P. (Org.). Gerenciamento em enfermagem. Rio de Janeiro: Guanabara Koogan, 2005.
CHIAVENATO, I. Gerenciando pessoas: passo decisivo para a administração participativa. 3. ed. São Paulo: Makron Books, 1994.

CONSElHO FEDERAL DE ENFERMAGEM. Conselho Federal de Enfermagem. Disponível em: <www. portalcofen.gov.br>. Acesso em: 15 jul. 2010.

CUNHA, I. C. K. O; NETO, F. R. G. X. Competências gerenciais de enfermeiras: Um novo velho desafio? Texto \& Contexto: Enfermagem, Florianópolis, v. 15, n. 3, jul.-set., p. 479-82. 2006.

FEUERWERKER, L. C. M; CECÍLIO, L. C. O. O hospital e a formação em saúde: desafios atuais. Ciência \& Saúde Coletiva, Rio de Janeiro, v. 12, n. 4, jul.-ago. p. 965-71, 2007.

GALVÃO, M. C. et al. Liderança e comunicação: estratégias essenciais para o gerenciamento da assistência de enfermagem no contexto hospitalar. Revista LatinoAmericana de Enfermagem, Ribeirão Preto, v. 8, n. 5, out. 2000, p. 34-43.

GELBCKE, F. L. et al. Liderança em ambientes de cuidados críticos: Reflexões e desafios à enfermagem brasileira. Revista Brasileira de Enfermagem, Brasília, v. 62, n. 1, jan.-fev., p. 136-39, 2009.

JERICÓ, M. C; PERES, A. M. Estrutura organizacional do serviço de enfermagem: reflexões sobre a influência do poder e da cultura organizacional. Revista da Escola de Enfermagem da USP, São Paulo, v. 42, n. 3, mar. p. 56977, 2008.

KURCGANT, P. Administração em enfermagem. São Paulo: EPU, 1991.

Gerenciamento em Enfermagem. Rio de Janeiro: Guanabara Koogan, 2005.

LEITE, M. M. J.; PEREIRA, L. L. Educação continuada em enfermagem. In: KURCGANT, P. Administração em enfermagem. São Paulo: EPU, 1991.

.; _ _. . et al. Educação continuada: recrutamento e seleção, treinamento e desenvolvimento e avaliação de desempenho profissional. In: KURCGANT, P. Gerenciamento em Enfermagem. Rio de Janeiro: Guanabara Koogan, 2005.

MARTINS, G. A; THEÓPHILO, C. R. Metodologia da investigação científica para as ciências sociais aplicadas. São Paulo: Atlas, 2007.

MASSAROLLO, M. C. K. B. Escalas de distribuição de pessoal de enfermagem. In: KURCGANT, P. Administração em enfermagem. São Paulo: EPU, 1991. 
MEDEIROS, T. G; SILVA, J. R. G. Os aspectos do comprometimento organizacional de profissionais terceirizados. Disponível em: <http://www.puc-rio.br/ pibic/relatorio_resumo2007/relatorios/ADM/adm_thiago_ goncalves_medeiros.pdf $>$. Acesso em: 10 ago. 2010.

MOSCOVICI, F. Equipes dão certo: a multiplicação do talento humano. 6. ed. Rio de Janeiro: José Olympio, 2001.

NEUMANN, V. L. Qualidade de vida no trabalho: percepções da equipe de enfermagem na organização hospitalar. Dissertação (Mestrado em Enfermagem). Escola de Enfermagem, Universidade Federal de Minas Gerais. Belo Horizonte, 2007.

ORGANIZAÇÃO MUNDIAL DA SAÚDE. Organização Mundial da Saúde. Disponível em: <www.who.int>. Acesso em: 10 jul. 2010.

PERES, A. M; CIAMPONE, M. H. T. Gerência e competências gerais do enfermeiro. Texto \& Contexto: Enfermagem. Florianópolis, v. 15, n. 3, jul.-set. p. 492-99, 2006.

PINHO, D. L. M; ABRAHÃO, J. I; FERREIRA, M. C; As estratégias operatórias e a gestão da informação no trabalho de enfermagem no contexto hospitalar. Revista Latinoamericana de Enfermagem, Ribeirão Preto, v. 11, n. 2, mar.-abr., p. 168-76, 2003.

RODRÍGUEZ, E. O. L. L; TREVIZAN, M. A; SHINYASHIKI, G. T. Reflexões conceituais sobre comprometimento organizacional e profissional no setor saúde. Revista Latino-americana de Enfermagem, Ribeirão Preto, v. 16, n. 5, maio-jun. 2008, p. 484-88.

SILVA, M. J. P. Comunicação tem remédio: a comunicação nas relações interpessoais em saúde. São Paulo: Loyola, 2002.

STRAPASSON, M. R; MEDEIROS, C. R. G. Liderança transformacional na enfermagem. Revista Brasileira de Enfermagem, Brasília, v. 62, n. 2, mar.-abr., p. 228-33, 2009.

ZANELLI, J. C; BORGES-ANDRADE, J. E.; BASTOS, A. V. B. Apresentação. In: ZANELLI, J. C; BORGES-ANDRADE, J. E.; BASTOS, A. V. B. (Orgs.). Psicologia, organizações e trabalho no Brasil. Porto Alegre: Artmed, 2004. 